\title{
La recepción y evolución de la imagen de Federico García Lorca en la Unión Soviética
}

\section{The Reception and Evolution of the Image of Federico García Lorca in the Soviet Union}

\author{
Alexandra Cheveleva Dergacheva \\ Investigadora independiente \\ acheveleva@tuamconsulting.com \\ ORCID iD: https://orcid.org/0000-0002-9565-2305
}

\section{RESUMEN}

La poesía de Lorca ha tenido una influencia enorme en la cultura literaria de la URSS, especialmente a partir de los años 60 a raíz del «deshielo» de Jruschov. En esta época, Lorca prácticamente personificaba toda la poesía española para la sociedad rusa y las traducciones del poeta al ruso crearon su propia corriente literaria de diálogo intercultural.

El objetivo de esta investigación es estudiar dicho fenómeno a través del prisma de los cambios socioculturales en la Unión Soviética y demostrar cómo la recepción inicial de Lorca, en principio totalmente propagandística, se convierte con el paso de tiempo en una vía de inserción de las ideas que luchan contra la misma propaganda. También se estudia la aparición del «mito» durante el proceso de recepción, la tergiversación de la imagen del poeta y de los hechos de su vida vinculada con las características socioculturales del país y de la época de su recepción.

Palabras Clave: traducción poética; Federico García Lorca; Unión Soviética; cultura literaria soviética; recepción de Lorca.

\begin{abstract}
Lorca's poetry had an enormous influence on the literary culture of the Soviet Union, especially after the 1960s Khrushchev's «Thaw». At that time Lorca almost personifies all Spanish poetry for Russian society. Lorca translations created their own literary trend of intercultural dialogue.

The goal of this paper is to study the phenomenon through the prism of socio-cultural changes in the Soviet Union and to demonstrate how the initial propagandistic reception of Lorca in the USSR gradually transforms to the way of insertion of the ideas fighting against the same propaganda. The paper also studies the appearance of the «myth» during the process of reception, the distortion of the image of the poet and the facts of his life caused by the sociocultural characteristics of the country and that time.
\end{abstract}


Key words: Poetry translation; Federico García Lorca; Soviet Union; Soviet literary culture; Reception of Lorca.

\section{INTRODUCCIÓN}

Federico García Lorca fue uno de los escasos poetas modernos extranjeros bien representados y conocidos en la Unión Soviética y uno de los que, sin duda, han tenido una importantísima influencia en la cultura literaria rusa, sobre todo a partir de principios de los años 60. Su poesía era un soplo de aire libre, casi la única voz que se podía oír desde el otro lado del telón de acero, un misterio, y poder leerlo fue en sí una pequeña protesta, lo que le ha convertido en un mito de la época de «deshielo» de Jruschov.

Las traducciones de Lorca crearon su propia corriente literaria de diálogo intercultural. Entre los primeros versos creados con evidente imitación del imaginario de Lorca, podríamos mencionar el poema Definición de la poesía de Jósef Brodsky, escrito en 1959, o Goya de Andréi Voznesenski, del mismo año, así como también Canción de García Lorca de Nikolai Aseev, publicado en su colección de poemas de 1961. Algunos poemas de Lorca, como Baile o La guitarra tienen hasta 20 traducciones publicadas y fueron traducidos por los grandes poetas rusos como Marina Tsvetáyeva (Иванов 1967: 5-18), Yunna Moritz o Nikolai Aseev.

Sirva como curiosidad que el más famoso traductor de Lorca, Anatoliy Geleskul, que a lo largo de su vida consiguió traducir todo el «corpus» conocido de su obra, fue, según afirma él mismo en la entrevista para el periódico Novoe Obozrenie (Калашникова 2008: 154-159), un autodidacta que aprendió español tras haberse enamorado de la poesía de Lorca. Se podría decir incluso que en Rusia, en la segunda mitad del siglo XX, casi no existe ningún poeta o escritor conocido que no le haya dedicado por lo menos algunas líneas. Sin embargo, el proceso de recepción y de asimilación de Lorca por la cultura soviética no ha sido nada fácil. El objetivo de esta investigación es estudiar dicho fenómeno a través del prisma de cambios socioculturales en ambos países y demostrar como la negación y luego la recepción propagandística inicial de Lorca en la URSS se convierte en una vía de inserción de la idea de la libertad y lucha contra la misma propaganda.

\section{ETAPA INICIAL}

La propaganda soviética en la época de Stalin y prácticamente hasta los años 60 seleccionaba en la literatura, sobre todo en la poesía extranjera, solo aquellas figuras que pudieran cumplir ciertos requerimientos: ser luchadores 
por los ideales comunistas, proceder preferiblemente de la estirpe campesina o ser víctimas del régimen. En este sentido, sus creaciones tenían que estar estrechamente vinculadas con el arte popular, hablar de los problemas sociales y, a la vez, cumplir con los criterios del realismo socialista. Estas figuras podían servir de bandera, de ejemplo de simpatía a las ideas comunistas para la política soviética $\mathrm{y}$, muchas de las veces, para la buena recepción de un autor $\mathrm{u}$ otro, tenía mayor importancia el cumplimiento de estos criterios que el verdadero valor de su obra. Los autores «reaccionarios» y «burgueses» como, por ejemplo, Miguel de Unamuno o Jacinto Benavente en el caso de España de aquella época estaban prácticamente prohibidos ${ }^{1}$.

Paradójicamente, muchos artistas y literatos verdaderamente simpatizantes con el régimen tampoco cumplían los criterios anteriormente citados y, por lo tanto, no llegaban a representar al país en las editoriales de la época soviética. Este fue el caso de Rafael Alberti, que, por su orientación surrealista, su emigración oportuna de España en 1936 y su origen burgués fue traducido y publicado solo muy selectivamente y con bastante cautela. Incluso durante el Primer Congreso de la Unión de Escritores Soviéticos de 1934, en su discurso de clausura, Máximo Gorki, haciendo una lista de «Literatos extranjeros antifascistas, líderes de sus lectores» no menciona a Alberti de ninguna forma (Горький 1953: 51) a pesar de que este estaba presente en el Congreso junto con su esposa, María Teresa León.

En este contexto no era nada sorprendente que durante su vida Lorca pasara totalmente desapercibido para la crítica soviética. Según Olga Musaeva (Мусаева 2009: 274; 2011), quizás la más importante historiógrafa de la recepción de Lorca en Rusia, hasta la misma fecha de su muerte aparece solo una vez, en concreto en el listado de los miembros de la Asociación de Amigos de la Unión Soviética (AUS) publicado en la revista de Socorro Rojo Internacional (SRI) en 1933. A su vez, en el artículo dedicado a los escritores y poetas revolucionarios de España, publicado en 1933 por Fyódor Kélyin (Кельин 1933: 157-162), uno de los hispanistas rusos más grandes de la época, se menciona a Ramón José Sender, Manuel Benavides, César Arconada, Joaquín Arderius, Isidoro Acevedo e incluso al «mal visto» Rafael Alberti, pero otra vez ni rastro de Lorca.

${ }^{1}$ Así, en la Enciclopedia Literaria de 1929-1939 (Лебедев-Полянский, Луначарский 1929-1939) no se menciona ni una obra publicada en ruso de Benavente y solo una de Unamuno. También se habla de, por ejemplo, las novelas de Unamuno que «no dan nada para el entendimiento real de la vida, llevan al callejón sin salida de paradojas o desesperación pesimista. Lo mismo se puede decir de su poesía y de sus obras de teatro». Texto original en ruso: «не дают ничего для реального осмысления жизни, заводят читателя в тупик парадокса или пессимистической безысходности. То же относится к стихам и драмам Унамуно» (T.11, pág. 525). De esa forma también se «tachan» la mayoría de los escritores y poetas de la época. 
Sin embargo, la situación cambió radicalmente cuando se confirmó definitivamente la noticia sobre el asesinato del poeta. Según Ian Gibson (1979), el mundo, en principio, no podía asimilar la noticia y este macabro ejemplo de las represiones fascistas fue algo nuevo para aquella época, de tal manera que hasta octubre de 1936 los medios de comunicación internacionales dudarían sobre la autenticidad del acontecimiento. Así, uno de los primeros reporteros que confirmó la noticia fue M. Koltzov, corresponsal de Pravda en España, que en su reportaje del 10 de septiembre de 1936 (Кольцов 1936: 4) decía lo siguiente: «Ahora finalmente se ha confirmado la ejecución en Granada del gran poeta y dramaturgo de España Federico García Lorca. Todo el país está de luto por la pérdida ${ }^{2} \gg$.

A partir de este momento, en la prensa de la Unión Soviética aparecen las notas necrológicas dedicadas al poeta y escritas por los famosos hispanistas de la época: Fyodor Kélyin (Кельин 1936: 4), David Vigódskiy (Выгодский 1936: 2) у Nikolai Gabínskiy (Габинский 1936a: 2; 1936b: 6-7). Desde estos obituarios empezará la construcción del «mito de Lorca» soviético, en principio puramente ideológico, y, aunque los hechos en general corresponden a la realidad, la manera de presentarlos seguirá una línea que permite crear una figura literaria de características requeridas por la propaganda de la época. El único hecho indiscutible — el fusilamiento de Lorca por los falangistas — se presenta de una manera periodística, emocional y evaluativa: Lorca fue matado por unos «mercenarios contratados por el fascismo internacional» (en el artículo de Gabínskiy - Габинский 1936b: 6), por los «verdugos fascistas» (Kélyin - Кельин 1936: 4).

Como era de esperar, el origen de Lorca procedente de una familia acomodada no se mencionaba: Vigódskiy (Выгодский 1936: 2) solo informa a los lectores de que Lorca nació en Granada; Gabínskiy indica que el poeta se graduó en la Facultad de Filología de la Universidad de Granada; Kélyin también menciona los estudios de Lorca en Madrid, y da una información errónea sobre los viajes del poeta por Francia, Inglaterra y Canadá y, en ningún caso, se menciona el viaje de Lorca a los Estados Unidos. Una de las posibles razones, según Olga Musaeva (Мусаева 2011: 16) podría ser el hecho de que este viaje coincidió en el tiempo con su trabajo sobre los dramas vanguardistas $E l$ Público (1930-1933) y Así que pasen cinco años (terminada en 1931), así como con Poeta en Nueva York, en el que Lorca está fuertemente influenciado por el surrealismo. Las tendencias surrealistas en las obras del poeta, teniendo en cuenta que el surrealismo fue una de las tendencias de vanguardia estimada en la Unión Soviética de aquel momento como algo inequívocamente negativo, fueron excluidas de la biografía de Lorca. Así, no sorprende que casi no se diga

2 Original en ruso: «Теперь окончательно подтвердилось сообщение о расстреле в Гранаде крупнейшего поэта и драматурга современной Испании Федерико Гарсиа Лорки. Вся страна оплакивает эту потерю» (Кольцов 1936: 4). 
nada sobre la personalidad de Lorca y que se describa solo su orientación política. Aunque Kélyin intenta introducir una amplia cita de Lorca sobre su poesía que no lleva ninguna carga ideológica, enseguida subraya que "García Lorca se olvida en esta frase de lo único y de lo más importante: de su estrecho vínculo con la poesía popular³» (Кельин 1936:4). Se habla de él como de un poeta con una actitud cívica activa, un simpatizante comunista. Kélyin y Gabínskiy informan a los lectores de que Lorca había firmado los manifiestos antifascistas y se enfatiza la afiliación de Lorca a los círculos de escritores revolucionarios, incluso atribuyéndole las publicaciones en la revista Octubre, según Olga Musaeva inexistentes (Мусаева 2011: 18). Y de esta manera empiezan los primeros elogios para la «canonización» de Lorca: «A la hora de la lucha heroica la literatura revolucionaria española pone, y con razón, su nombre a la bandera como el nombre del poeta y dramaturgo español más grande del siglo $\mathrm{XX}^{4} \gg$ (Anónimo 1936a).

Kélyin y Vygódskiy en algunos casos son más cautelosos que otros autores en la evaluación de la posición política del poeta y las ideas reflejadas en su trabajo. Por ejemplo, Vigódskiy escribe: «García Lorca incluía los temas revolucionarios en su trabajo, pero estando, sin embargo, "al margen de la lucha"; hasta casi el último momento estaba entre aquellos que intentaban romper el vínculo entre la poesía y la lucha político-revolucionaria ${ }^{5}$ » (Выгодский 1936: 2).

Por otro lado, desde el punto de vista estético, se subrayan los temas folclóricos en la obra de Lorca, algo que fue imprescindible para hacer posible su recepción por la sociedad soviética de aquella época. En el mismo Primer Congreso de la Unión de los Escritores Soviéticos (1934) Máximo Gorki diría que:

La palabra del arte proviene del folklore. Recoged vuestro folklore, aprended de él, utilizadlo. Él os dará una gran cantidad de material - a vosotros y a nosotros, poetas y prosistas de la Unión. Cuanto mejor conocemos el pasado, más fácilmente y más profundamente entenderemos el gran significado de la obra que estamos haciendo ${ }^{6}$ (Горький 1953: 49).

${ }^{3}$ Original en ruso: «Гарсия Лорка забывает в этом высказывании об одном и самом главном - о своей связи с народной поэзией».

${ }^{4}$ Original en ruso: «B час героической борьбы испанская революционная литература по праву выставляет на своем знамени имя величайшего народного поэта и драматурга Испании XX века»

${ }^{5}$ Original en ruso: «Гарсиа Лорка не чуждался революционных тем в своем творчестве, но стоял, однако, “в стороне от схватки” и еще недавно был в ряду тех, которые пытались оторвать поэзию от вопросов современности, от социальнополитической борьбы» (Выгодский 1936).

${ }^{6}$ Original en ruso: «Начало искусства слова - в фольклоре. Собирайте ваш фольклор, учитесь на нем, обрабатывайте его. Он очень много дает материала и вам, и нам, поэтам и прозаикам Союза. Чем лучше мы будем знать прошлое, тем легче, тем 
Por eso las primeras obras de Lorca que se destacan en los obituarios son las que contienen elementos folclóricos o político-sociales: Kélyin menciona el Libro de Poemas (1921) y el Romancero gitano (1928) (Кельин 1936) у Gabínskiy, por su parte, escribe que «...muchos de sus poemas, difundidos entre las masas, se han convertido en verdaderas obras de folclore, perdiendo el nombre de su creador ${ }^{7}$ (Габинский 1936b: 6). Hay que subrayar que el mero hecho de poder preparar un obituario tan rápido (Fyódor Kélyin escribió un texto bastante elaborado, con varias citas y numerosos detalles biográficos del poeta, en tan solo en 3 o 4 días) en aquella época, cuando el acceso a la información era lento y limitado, ya significaba que los hispanistas rusos estaban siguiendo la vida de Lorca de cerca, pero solo la muerte del poeta y quizás una orden oficial para empezar la «campaña de inclusión» en la lista de los poetas «ideológicamente aceptados» les permitió hablar de él.

Una prueba documental de que durante la vida de Lorca ya existía un contacto «oficioso» es una carta de Alberti a Kélyin de principios del año 1936 citada por Hilario Jiménez Gómez (2009: 121) que dice lo siguiente:

Querido Kélyin:

El que está comiendo con nosotros es Federico García Lorca, que está deseando ir a Rusia para conocerla y conocerte. Mándale la traducción de su poema y escríbele. Vive Alcalá 102, Madrid.

Abrazos,

La posibilidad de que antes de la muerte de Lorca ya existían traducciones de algunas de sus obras en ruso también se confirma por un anuncio publicado en Literaturnaya Gazeta el 30 de septiembre de 1936 (Anónimo 1936b: 5). Allí se informa de la próxima publicación de la colección de obras de los poetas españoles y, a pesar de que hubiera pasado muy poco tiempo desde la llegada de la noticia sobre su muerte, ya se subraya que, entre otros nombres, se van a publicar las obras del poeta García Lorca, «fusilado por los rebeldes». Lamentablemente, este libro nunca vio la luz y es posible que por una simple razón: en agosto-septiembre de 1936 Stalin había empezado «la gran limpieza de los recursos humanos». Los grandes hispanistas rusos como Rakhmánov o Vigódskiy, en otoño de 1936, fueron echados de sus trabajos, luego arrestados y murieron en campos de concentración unos años después; Ilia Erenburg, por su parte, se quedó en España hasta el último momento de la guerra civil y

более глубоко и радостно поймем великое значение творимого нами настоящего» (Горький, 1953: 49).

${ }^{7}$ Original en ruso: «многие его произведения, уйдя в народные массы, превратились в подлинно фольклорные произведения, потеряв имя их создателя» (Габинский 1936b: 6) 
luego huyó a París; entre los hispanistas importantes de la época, solo Kélyin y Parnakh se salvaron de las represiones. Posiblemente por ello y a pesar del evidente interés hacía la obra de Lorca, sus primeras publicaciones en ruso se retrasaron significativamente en el tiempo.

LAS PRIMERAS PUBLICACIONES (1937 - FINAL DE LOS 50)

Durante las décadas de 1930 a 1950 los traductores, críticos e investigadores soviéticos trataron de ver en las obras de Lorca, en primer lugar, dos componentes: la problemática social y clasista y el tema folclórico. En este sentido, se hace todo lo posible para «encuadrar» a Lorca en el marco del «poeta revolucionario» y así hacer posible la recepción y la divulgación de su obra. Para la entrada en la literatura soviética existía un camino ya definido, los críticos ya habían elaborado un esquema que los escritores extranjeros debían cumplir estrictamente. La aceptación de Lorca en la corriente principal de la poesía soviética de la época solo podía ir en una dirección: los críticos tenían que hacer hincapié en los temas «revolucionarios», en la «actitud ciudadana» $\mathrm{y}$ en las raíces folclóricas de su creatividad (en este sentido el tema gitano fue especialmente útil y no en vano los poemas del Romancero gitano fueron los más traducidos durante toda la época soviética); luego tenían que compararle y establecer su relación con otros poetas que ya habían adquirido la condición de «revolucionarios» (en este contexto Rafael Alberti, que publicó varios artículos sobre Lorca en los años 37-39 (Альберти 1938 у 1939), facilitó la inserción de Lorca al círculo de los poetas «permitidos» y publicados); y, por último, subrayar su desarrollo desde las corrientes de vanguardia hacía el realismo, y su conexión con la historia de su país y la literatura clásica española.

De esta manera, la manipulación de los hechos conocidos de la biografía del poeta permitió crear un mito adecuado y Lorca entró en el panteón de los poetas aceptados por la censura soviética, pero, evidentemente, esto requería una tergiversación tan importante que a veces los resultados eran casi anecdóticos. Por ejemplo, el vínculo de Lorca con el pueblo gitano fue tan propagado durante la época, que hasta ahora en la tradición literaria rusa fuera del ámbito académico, a pesar de todos los hechos biográficos ya conocidos, de vez en cuando se habla del «origen gitano» de Lorca o incluso le llaman «el gitano» directamente. Un buen ejemplo de este equivoco común es el artículo «Цыгане» («Gitanos») de la Wikipedia rusa $^{8}$, donde hasta ahora aparece oficialmente en la lista de los gitanos famosos. Los críticos probablemente fueron conscientes

${ }^{8}$ Wikipedia. «Цыгане». http://ru.wikipedia.org/wiki/цыгане (consultado: julio 2019, idioma: ruso, fuente abierta) 
de que la imagen creada por ellos estaba muy lejos de la verdadera identidad de Lorca, pero era el único camino posible.

Antes de la Segunda Guerra Mundial se realiza un importantísimo trabajo de estudio y de traducción de las obras de Lorca. Los primeros traductores fueron David Vigódskiy, que antes de su arresto consiguió publicar un poema de Lorca en el periódico Zvezda (Гарсия Лорка 1937), y luego Fyodor Kélyin, que publicó la primera edición independiente de Lorca en ruso de Bodas de Sangre, que vio la luz en 1939 (Гарсия Лорка 1939). A su vez, durante este periodo aparecieron en periódicos y en revistas literarias las traducciones de $\mathrm{V}$. Parnakh, N. Aseev, A. Fevralskiy, A. Golberg y S. Bobrov, entre otros. En 1941 Fyodor Kélyin empieza la preparación de la edición de obras selectas de Lorca y encarga la traducción de varias de ellas a Marina Tsvetáyeva (Азадовский 2009), quizás la poetisa más brillante de la Edad de Plata de la poesía rusa y para quien esta traducción, lamentablemente, se convirtió en el último (y no terminado) trabajo de su vida antes de su suicidio en 1941. Las primeras obras de Lorca que se traducen al ruso son Mariana Pineda, Bodas de sangre, Yerma y La zapatera prodigiosa, así como una selección de poemas de Romancero gitano, Libro de poemas, Canciones, Poemas del cante jondo y Llanto por Ignacio Sánchez Mejías.

La llegada de la Segunda Guerra Mundial impide la publicación de esta selección de obras de Lorca, y el libro ve la luz solo en 1944 (Гарсия Лорка 1944). Evidentemente, en el prefacio del libro escrito por F. Kélyin aparecen las características «ideológicamente correctas» de las obras publicadas: por ejemplo, Mariana Pineda, igual que en los obituarios de 1936, se describe solamente como el himno de la lucha del pueblo hispano contra la monarquía, dejando al margen toda la línea de pasión y amor (Гарсия Лорка 1944: 3-15). Sería interesante comparar esta interpretación con el testimonio del mismo Lorca, quien en su carta a Melchor Fernández Almagro de septiembre del año 1923 escribió:

Mariana, según el romance y según la poquísima historia que la rodea, es una mujer pasional hasta sus propios polos, una posesa, un caso de amor magnífico de andaluza en un ambiente extremadamente político (no sé si me explico bien). Ella se entrega al amor por el amor, mientras los demás están obsesionados por la Libertad. Ella resulta mártir de la Libertad, siendo en realidad (según incluso lo que se desprende de la historia) víctima de su propio corazón enamorado y enloquecido» (Marful Amor 1991: 59).

Esta edición de 1944, publicada con una tirada de 20.000 ejemplares, hasta el año 1957 fue el único libro de poesía de Federico García Lorca disponible para un lector rusohablante (aparte de los artículos de críticos literarios y las traducciones sueltas que aparecen de vez en cuando en los periódicos y revistas). Pero a partir del momento de su publicación, la poesía de Lorca ocupará un lugar importante en la cultura soviética. 
En este período, Lorca fue traducido, analizado e incluso imitado por los mejores traductores hispanistas: N. Aseyev, V. Parnakh, K. Gusev, V. Ilyiná, B. Zagorskiy, M. Zenkevich, I. Tynianova... Sus cuatro obras teatrales publicadas en la edición de 1944, sobre todo Bodas de sangre, desde entonces y hasta ahora forman una parte significativa del repertorio del teatro gitano «Romén» de Moscú (el teatro gitano más antiguo y más grande del mundo) y de muchos grupos teatrales de menor importancia.

Sin embargo, se puede decir que la tradición poética lorquiana todavía se queda en aquel momento fuera del contexto de la poesía rusa: hay pocas imitaciones, pocas influencias; es una figura más bien exótica, poco asimilada, no existe la tradición de aemulatio, el discurso lorquiano en la poesía rusa todavía no está formado. Se trata de una figura representativa de los acontecimientos y tragedias importantes de la historia moderna de España (en aquella época muy recientes) y nada más.

\section{LA ÉPOCA DE DESHIELO Y LA TRANSICIÓN ESPAÑOLA: LA VOZ DEL OTRO LADO DEL TELÓN DE ACERO}

Cuanto más se sabe sobre el poeta, más difícil resulta mantener su imagen de cartulina creada inicialmente por y para la propaganda. Además, en la Unión Soviética se acaba la época del gobierno de Stalin y la censura se debilita, lo que permite publicar a los autores extranjeros con más libertad.

En los años 1957 y 1960, justo antes y al principio de la época de deshielo de Nikita Jruschov, aparecen las nuevas antologías de Lorca (Гарсия Лорка 1957 y 1960). En la edición de 1960 ya se publican las traducciones de los libros de poemas anteriormente «mal vistos» por la censura, como eran Diván del Tamarit y Poeta en Nueva York. El libro se publica con una introducción de Eusebio Cimorra, periodista comunista español exiliado en aquella época en Rusia, en la que su relato sobre Lorca, a pesar de su carga ideológica, es mucho más humano e incluye recuerdos personales y detalles costumbristas de un testigo presencial ${ }^{9}$.

9 Así, Cimorra da muchos detalles de la infancia de Lorca, como la descripción de la actuación de un teatro de títeres que pasaba por Granada (Гарсия Лорка 1960: 5), de su vida cotidiana de pequeño: «De pequeño, Lorca solía ir al colegio en tranvía; el colegio estaba situado en la ciudad, en la antigua Granada [...] Aquí este pequeño muchacho se empapaba de líneas y colores, que luego afloraron tanto en su poesía como en sus pinturas» («В школу маленький Лорка ездил на трамвае, а помещалась школа в городе, в старинной Гранаде [...] Здесь мальчик впитывал линии и краски, которыми потом овладел и в поэзии, и в живописи») (Гарсия Лорка 1960: 6), о de su juventud «Él ya es estudiante de la universidad de Madrid. No tiene todavía ni veinte años. Tiene muchos amigos. A menudo toca piano de cola y guitarra» («Затем он - студент Мадридского университета. Ему еще нет двадцати. У него много друзей. Он часто играет на рояле 
Al final del deshielo el interés hacía Lorca es enorme: su obra se convierte en conocimiento obligatorio para cualquier intelectual representante de la inteligentzia soviética de los 60, shestidesyátniki (sixtiers). En los años 1965-1966 salen una tras otra dos ediciones de la misma colección de poemas de Lorca (Гарсия Лорка 1965 у 1966) - la primera, publicada en la serie «Los tesoros de la poesía lírica», que confiere al autor el status de poeta clásico, no consigue cubrir la demanda, a pesar de su tirada de 50.000 ejemplares- - La otra colección de poemas, que en gran medida repite la edición exitosa de 1965-1966, sale en 1969 (Гарсия Лорка 1969). También en 1965 se publica una voluminosa biografía de Lorca escrita por Lev Ospovat (Осповат 1965), donde el poeta se describe con una actitud mucho más humana que en los artículos de los años anteriores; se habla de su misticismo, de su vulnerabilidad, aparecen algunos pequeños detalles biográficos e incluso se habla de forma ambigua sobre sus «amistades» masculinas, aunque el revelador libro de Ian Gibson (Gibson 1979) aparece solo 15 años más tarde.

Es importante mencionar que al final de los 50 el mismo proceso de asimilación cultural por la cultura soviética incluye en el círculo de lectura a muchos poetas y escritores extranjeros, entre ellos (y eso ha tenido una influencia importantísima para la recepción de Lorca) a Ernest Hemingway y su libro Por quién doblan las campanas. El interés hacia España crece y los eventos de la Guerra Civil ya se ven desde el punto de vista antimilitarista, menos influenciado por la ideología; para muchos literatos de la época, Hemingway y Lorca se perciben juntos como representantes de una cultura occidental diferente, llaman la atención y se imitan.

En general, a partir del Deshielo (1961) en la cultura de habla rusa Lorca se percibe con más cariño, con cierta ternura; la censura ya deja que sean visibles los rasgos místicos, míticos y surrealistas de sus obras, ya se habla de las hadas y del «duende» de su poder creativo. Como una avalancha, durante la época de Jruchov y los primeros años de la época de Brézhnev, aparecen las imitaciones de su poesía, ensayos y «ciclos españoles» en la obra de los poetas soviéticos.

Este interés también se estimula con la Transición española. Por fin España, aunque sigue siendo un país del otro lado del telón de acero, ya no es un enemigo directo. Algunos de los niños de la guerra españoles después de treinta años de espera obtienen el permiso de volver a casa y en las universidades rusas aparecen estudiantes de España. Por fin se publican las obras de muchos escritores españoles, anteriormente mal vistos por la censura. Y la introducción

или гитаре...») (Гарсия Лорка 1960: 6). Asimismo, Cimorra reproduce varias citas de la última entrevista a Lorca realizada por Luís Bagaría (Гарсия Лорка 1960: 9). A pesar de que algunos detalles, posiblemente, fueran fruto de la fantasía del mismo Cimorra (como, por ejemplo, escenas del teatro de títeres descritas en el texto), dan una imagen cálida y humana del poeta. 
de Lorca en la cultura rusa se convierte casi en un vector principal de este proceso de acercamiento cultural.

En este contexto, especialmente destaca la verdadera hazaña de A. Geleskul. Sin formación en filología, pero enamorado de la poesía de Lorca y disponiendo de un don excepcional para la traducción (aprendió el español descifrando las obras de Lorca con un diccionario) llegó a dominar el idioma y dedicó su vida a la divulgación de la obra del poeta, consiguiendo traducir la obra completa de Lorca conocida hasta el año 2000. Hoy en día sus traducciones y sus artículos sobre Lorca están incluidos — y con razón — en la tesorería del saber de la tradición lorquiana rusa.

La melodía de la poesía de Lorca, su biografía, su estilo tan exótico para la cultura rusa atrae prácticamente a todos los poetas importantes de la época soviética. Casi todos ellos tienen poemas o ensayos dedicados a Lorca: Yevgeni Evtushenko «Cuando mataron a Lorca» (Евтушенко 1969), Andréi Voznesenski «Amo a Lorca» (ensayo en verso libre) (Вознесенский 1984), Robert Rozhdéstvenski «La guitarra de García Lorca» (Рождественский 1985: 121), Jósef Brodsky «A la memoria de García Lorca» (Бродский 1965), etc. Es de resaltar la reseña que Andrei Voznesenski (Вознесенский 1984: 355) le hace, en la que en breves palabras consigue expresar el significado de Lorca para la tradición poética rusa y el deseo de acercamiento a la tradición lorquiana que existía en las últimas décadas de la Unión Soviética:

Amo a Lorca. Me encanta su nombre - una ligera barca volando en el mar, la roca, la orca. Un zumbido de un sensible radar, una lámina lunar, el olor amargo y penetrante como el de la cáscara de naranja...

¡Lorca!

Él era el vagabundo, el actor, el soñador y el artista. De Falla dice que su don de músico no era menor que el don del poeta.

Nunca he visto a Lorca. Llegué tarde para nacer. Pero me reúno con él todos los días.

Cuando veo las dos lunas, lúbricas y puras - una en el río y la otra en el cielo,

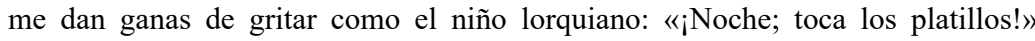
Cuando digo «Córdoba» ya veo estas dos nebulosas Córdobas, la de arquitectura y la de nenúfares, mezcladas en el agua de medianoche. Conozco su corazón, vulnerable, transparente como la seda, movido por la luz y por el sonido de campanillas. No conozco ninguna obra poética con más exactitud psicológica que su «La casada infiel». ¿Qué pureza, qué sentimientos tan anacarados! Me gusta oír en sus baladas cómo los gitanos y los serafines tocan juntos los acordeones...

Le mataron los franquistas el 18 de agosto de 1936.

Los criminales tratan de explicar esto como un accidente. ¡Oh, esos «errores»! ¿Acaso el asesinato de Pushkin fue también un malentendido? ¿Y Lérmontov una coincidencia? ${ }^{10}$

10 Original en ruso: «Люблю Лорку. Люблю его имя - легкое, летящее как лодка, как галерка - гудящее, чуткое как лунная фольга радиолокатора, пахнущее горько и 


\section{Conclusiones}

Jaques Derrida, al hablar de la deconstrucción en la traducción, decía:

Para que la fuente a su vez se haga imagen, a la vez que se comprometa en una trópica o en una fantasmática y para que se aparezca y se reciba, para que se vea como mirada de origen, debe dividirse. Por todas partes donde interviene el espejo, $[\ldots]$, la fuente no puede reencontrarse como efecto de espejo sino para perderse dos veces (Derrida 1988: 325).

Hablando del mismo tema desde el punto de vista de la retórica, Tomás Albaladejo (1998: 33), en su comentario a los tipos de traducción propuestos por Emilio Betti, afirma que la interpretación en función cognoscitiva o recognoscitiva es una primera e imprescindible fase de cualquier otra traducción, sea esta en función reproductiva o representativa. Pero este proceso cognoscitivo (o deconstructivo) es característico no solo para la traducción en sí. En el tema de la recepción y asimilación de todo el corpus de la obra de un poeta, en la posibilidad de aemulatio de su obra en otra cultura, pasa lo mismo: para entrar en otro entorno cultural, para formar una parte ya inalienable de él, la imagen del autor también se deconstruye y se crea de nuevo ya como un mito en el marco del discurso y de connotaciones culturales del otro país y de la otra lengua.

Esto pasaba también con Tolstói o Pushkin durante su recepción en la cultura europea. Y, como pretende demostrar este trabajo, lo mismo pasó con Lorca en la Unión Soviética: este fenómeno de creación de una figura nueva, mítica y asimilable por otra cultura, la creación de un «Federico ruso» se hace evidente cuando analizamos su recepción en la URSS. El proceso de asimilación de la figura del poeta, empezado por la invención de una imagen creada para los fines de la propaganda, refleja todos los cambios sociales y culturales del país de aquella época. Y, por otro lado, podemos observar que cuanto más acerque a los hechos de la vida y de la obra del poeta esta imagen inventada,

пронзительно как кожура апельсина... / Лорка!.. / Он был бродягой, актером, фантазером и живописцем. Де Фалла говорил, что дар музыканта в нем - не менее поэтического. / Я никогда не видел Лорки. Я опоздал родиться. Я встречаюсь с ним ежедневно. / Когда я вижу две начищенные до блеска луны - одну в реке, а другую на небе, мне хочется крикнуть, как лорковскому мальчугану: “Полночь, ударь в тарелки!” Когда мне говорят “Кордова", я уже знаю ее - эти две туманные Кордовы, “Кордову архитектуры и Кордову кувшинок", перемешанные в вечерней воде. Я знаю его сердце, ранимое, прозрачное, “как шелк, колышимое от луча света и легкого звучания колокольчика". И не знаю вещи, равной по психологической точности его "Неверной жене". Какая чистота, жемчужность чувства! Люблю слушать, как в его балладах цыгане и серафимы играют на аккордеонах... / Его убили франкисты 18 августа 1936 года. / Преступники пытаются объяснить это случайностью. Ах, эти “ошибки”! ...Пушкин - недоразумение? Лермонтов - случайность?!» 
cuanto más multidimensional se haga, más influencia es capaz de causar su obra en la cultura destino.

Este proceso ha continuado hasta ahora, como puede constatar el hecho de que cada año los fondos de la Biblioteca Estatal de Rusia se enriquecen con 4-5 ediciones nuevas dedicadas a la traducción o al estudio literario o biográfico de Lorca. El Lorca ruso, de esta manera, todavía se transforma por la cultura destino, se enriquece con ella y a su vez la nutre, se interioriza, produce nuevas obras e influencias.

Hay dos Federicos: el de la verdad y el de la leyenda. Y los dos son uno solo. Hay tres Federicos: el de la poesía, el de la vida y el de la muerte. Y los tres son un solo ser. Hay cien Federicos y cantan todos ellos. Hay Federicos por todo el mundo. La poesía, su vida y su muerte se han repartido por la tierra. Su canto y su sangre se multiplican en cada ser humano. Su breve vida crece y crece. Su corazón destrozado estaba repleto de semillas: no sabrán los que lo asesinaron que lo estaban sembrando, que echaría raíces, que seguiría cantando y floreciendo en todas partes y en todos los idiomas, cada vez más sonoro, cada vez más viviente (Neruda 1982: 108).

\section{BIBLIOGRAFÍA CITADA}

\section{ESPAÑOL}

Albaladejo Mayordomo, Tomás (1998). «Del texto al texto. Transformación y transferencia en la interpretación literaria», en Estanislao Ramón Trives y Herminia Provencio Garrigós (eds.), Estudios de lingüística textual. Homenaje al Profesor Muñoz Cortés. Murcia: Universidad de Murcia, pp. 31-46.

Derrida, Jaques (1988). Márgenes de la filosofía. Madrid: Cátedra.

Gibson, Ian (1979). Granada en 1936 y el asesinato de Federico García Lorca. Granada: Crítica.

Jiménez Gómez, Hilario (2009). Alberti y García Lorca: la difícil compañía. Sevilla: Editorial Renacimiento.

Marful Amor, Inés (1991). Lorca y sus dobles: interpretación psicoanalitica de la obra dramática y dibujística. Kassel: Edition Reichenberger.

Neruda, Pablo (1982). Para nacer he nacido. Barcelona - Caracas - México: Seix Barral.

RUSO

Anónimo (1936а). «Некролог Ф. Гарсиа Лорке», Интернациональная литература. 11, p. 60 .

Anónimo (1936b). «Советские поэты - героям Испании», Литературная газета. 55 $(618,30$ сент) р.5

Азадовский, Константин [Azadovski, Konstantin] (2009). «“Мне очень понравился Лорка...” Письмо Марины Цветаевой к Ф. В. Кельину. Публикация, вступительная заметка и примечания», Журнал Звезда. 6, pp. 154-156. 
Альберти, Рафаэль [Alberti, Rafael] (1938). «Федерико», Интернациональная литература. 8, pp. 128-129

Альберти, Рафаэль [Alberti, Rafael] (1939). «Памяти Гарсии Лорки» / Пер. с исп. Н. Любимова, Литературный критик. 3, pp. 165-177.

Бродский, Иосиф [Brodsky, Jósef] (1965). Стихотворения и поэмы. Washington - New York: Inter-Language Literary Associates.

Вознесенский, Андрей [Voznesenski, Andréi] (1984). Прорабы духа. Москва: Советский писатель.

Выгодский, Давид [Vigódskiy, David] (1936). «Федерико Гарсия Лорка», Литературный Ленинград. 43 (188) de 17/09, p. 2.

Габинский, Николай [Gabínskiy, Nikolai] (1936a). «Федерико Гарсиа Лорка», Советское искусство. 45 (29), p. 2.

Габинский, Николай [Gabínskiy, Nikolai] (1936b). «Федерико Гарсиа Лорка», Книжные новости. 27, рр. 6-7.

Гарсиа Лорка, Федерико [García Lorca, Federico] (1937). Баллада о морской воде. Стихи. Перевод с испанского Д. Выгодского. Звезда, 1937, N9, р. 69

Гарсиа Лорка, Федерико [García Lorca, Federico] (1939). Кровавая свадьба. Пер. с исп. Ф.В. Кельина и А.В. Февральского. Москва: Гос. издательство «Искусство».

Гарсиа Лорка, Федерико [García Lorca, Federico] (1944). Избранное. Предисл. Ф. В. Кельина. Москва: Гос. изд-во художественной литературы.

Гарсиа Лорка, Федерико [García Lorca, Federico] (1957). Театр. Сост. и примеч. Н. Медведева и 3. Плавскина; вступ. ст. Ф. Кельина. Москва: Искусство.

Гарсиа Лорка, Федерико [García Lorca, Federico] (1960). Избранная лирика. Сост. Ф. Кельин. Москва: Гослитиздат.

Гарсиа Лорка, Федерико [García Lorca, Federico] (1965). Лирика. 1-е изд. Москва: Художественная литература.

Гарсиа Лорка, Федерико [García Lorca, Federico] (1966). Лирика. 2-е изд. Москва: Художественная литература.

Гарсиа Лорка, Федерико [García Lorca, Federico] (1969). Лирика. Москва: Художественная литература.

Горький, Максим [Gorki, Máximo] (1953). Собрание сочинений в тридиати томах. Том 27. Статьи, доклады, речи, приветствия (1933-1936). Москва: ГИХЛ.

Евтушенко, Евгений [Evtushenko, Yevgeni] (1969). Идуm белье снеги. Москва: Художественная литература.

Иванов, В. [Ivanov, V.] (1967) «О переводах Марины Цветаевой». Просто сердие: Стихи зарубежных поэтов в переводе Марины Цветаевой. Москва: Прогресс, pp. 5-18.

Калашникова, Елена [Kaláshnikova, Elena] (2008). По-русски с любовью. Беседы с переводчиками. Москва: Новое литературное обозрение.

Кельин, Федор [Kélyin, Fyodor] (1933). «Революционная литература Испании на подъеме», Интернациональная литература. 4, pp. 157-162.

Кельин, Федор [Kélyin, Fyodor] (1936). «Федерико Гарсиа Лорка», Литературная газета. 52 (615; 15 сент.), р. 4.

Кольцов, Михаил [Koltzov, М.] (1936). «Корреспонденции о военно-фашистском мятеже в Испании», Правда. 250 (10 сент.), р. 4.

Лебедев-Полянский, Павел; Луначарский, Анатолий et al. [Lebedev-Polianskii, Pavel; Anatoli Lunacharski] (1929-1939). Литературная энциклопедия: В 11 m. Москва: изд-во Ком. Акад. 
Мусаева, Ольга [Musaeva, Olga] (2011). Рецепция творчества Федерико Гарсиа Лорки в русской культуре (1930-1960-е г2.). Научные руководители: Роман Лейбов, Леа Пильд. Tesis doctoral. Universidad de Tartu.

Мусаева, Ольга [Musaeva, Olga] (2009). «Федерико Гарсиа Лорка в советской периодике 1930-х гг.: особенности рецепции». Труды по русской и славянской филологии. Литературоведение: Новая серия, VII. Тарту. pp. 272-289.

Осповат, Лев [Ospovat, Lev] (1965). Гарсиа Лорка. Москва: Молодая гвардия.

Рождественский, Роберт [Rozhdéstvenski, Robert] (1985). Собрание сочинений в трех mомах, т. 3. Москва: Художественная литература.

Fecha de recepción: 08 de septiembre de 2016.

Fecha de aceptación: 06 de febrero de 2017. 